\title{
Ordering of Poly(3-hexylthiophene) in Solutions and Films: Effects of Fiber Length and Grain Boundaries on Anisotropy and Mobility
}

\author{
Nabil Kleinhenz ${ }^{1}$, Nils Persson ${ }^{2}$, Zongzhe Xue ${ }^{2}$, Ping Hsun Chu ${ }^{2}$, Gang Wang ${ }^{2,3}$, Zhibo Yuan ${ }^{1}$, \\ Michael McBride ${ }^{2}$,Dalsu Choi ${ }^{2}$, Martha Grover ${ }^{2 *}$ and Elsa Reichmanis ${ }^{1,2,4 *}$ \\ ${ }^{1}$ School of Chemistry \& Biochemistry, Georgia Institute of Technology, Atlanta, GA, USA \\ ${ }^{2}$ School of Chemical \& Biomolecular Engineering, Georgia Institute of Technology, Atlanta, GA, USA \\ ${ }^{3}$ State Key Laboratory for Modification of Chemical Fibers and Polymer Materials, College of Material Science and \\ Engineering, Donghua University, Shanghai 201620, People's Republic of China \\ ${ }^{4}$ School of Materials Science \& Engineering, Georgia Institute of Technology, Atlanta, GA, USA.
}


(a)
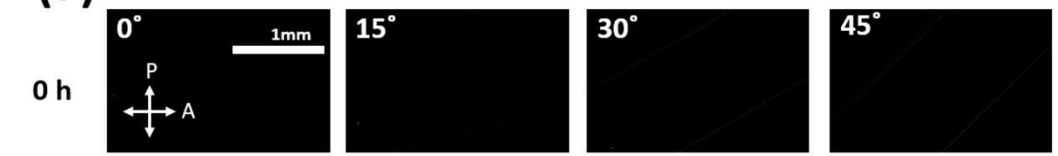

$12 \mathrm{~h}$

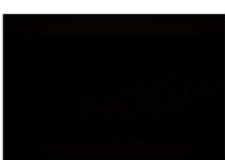

$24 \mathrm{~h}$
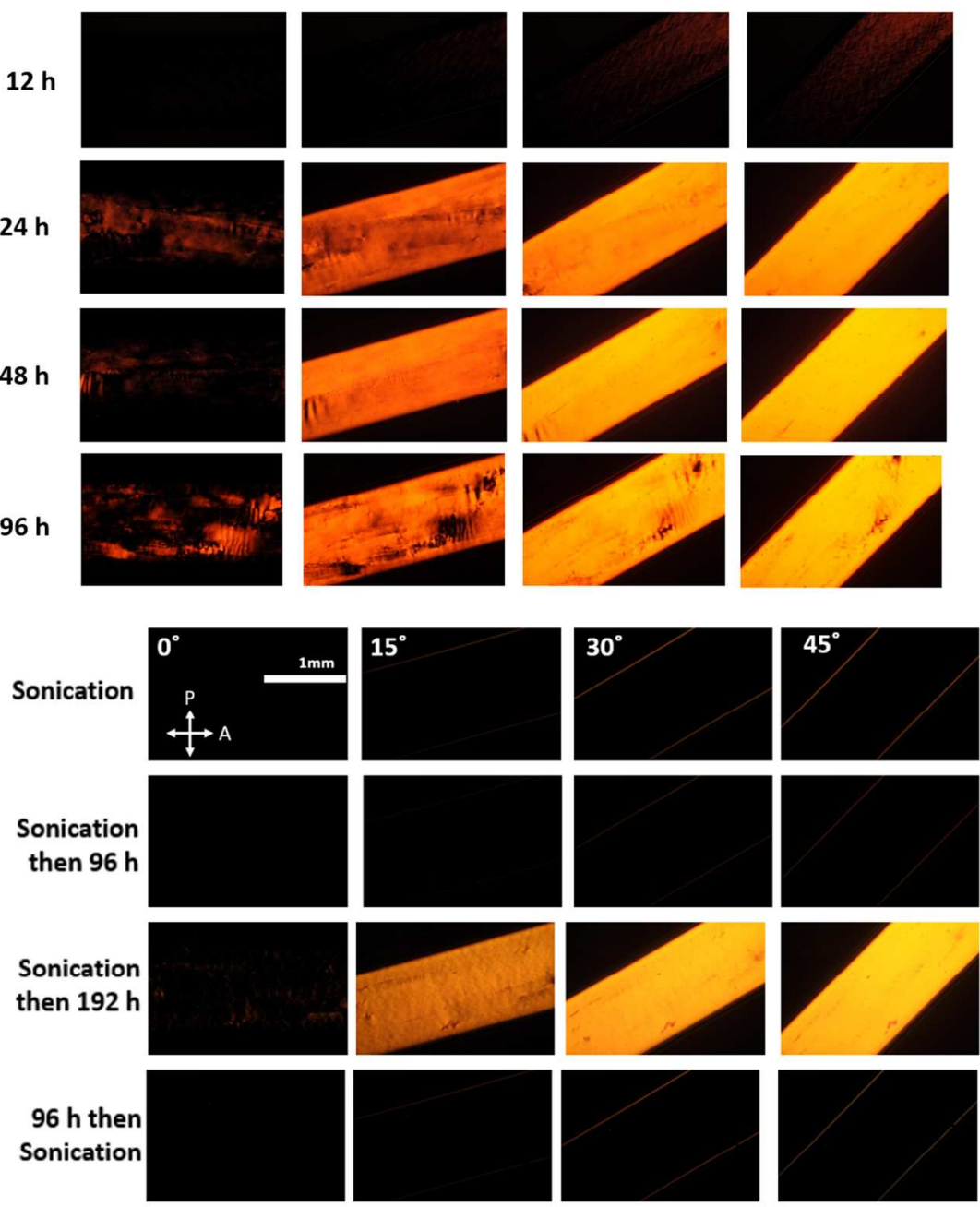

(b)
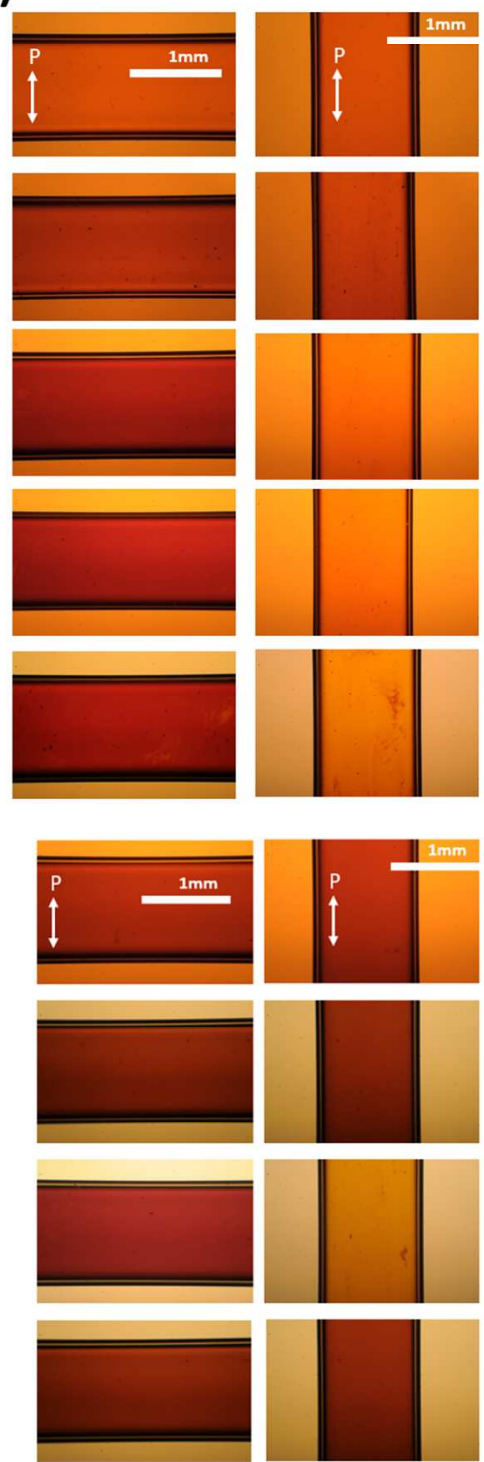

Figure S1: (A) Polarized Optical Microscopy (POM) images of capillaries filled with $5 \mathrm{mg} / \mathrm{mL}$ $\mathrm{P} 3 \mathrm{HT} / \mathrm{Chloroform}$ solutions processed as indicated, before filling. Angles refer to angle between long axis of capillary and analyzer. (B) Images taken with only one polarizer, showing linear dichroism as capillary is oriented parallel or perpendicular to polarizer. Suggests chains are perpendicular to capillary long-axis and fibers are parallel to capillary long-axis. 
(a)
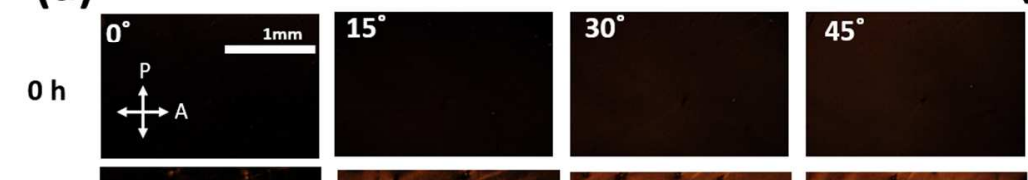

(b)
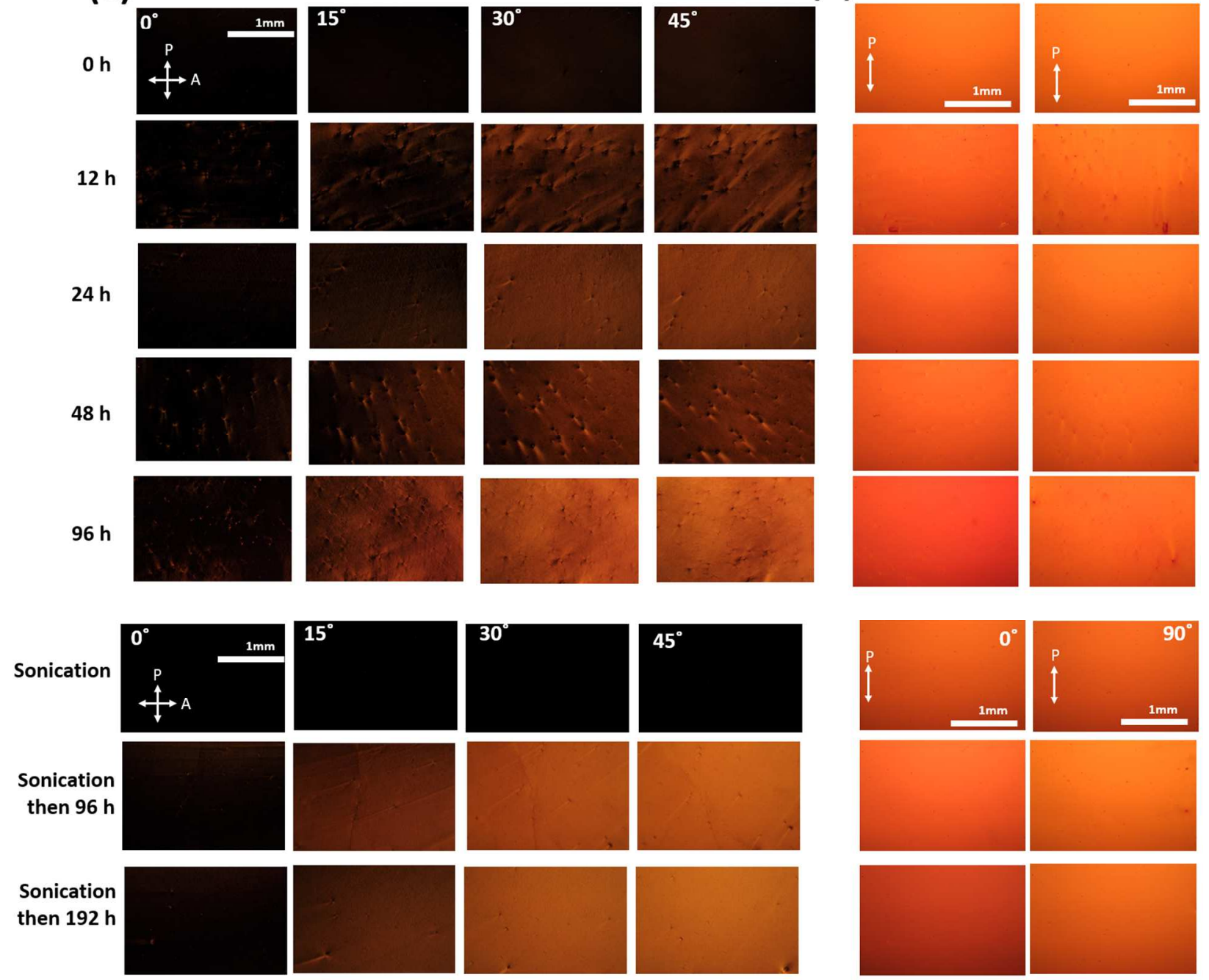

$96 \mathrm{~h}$ then

Sonication
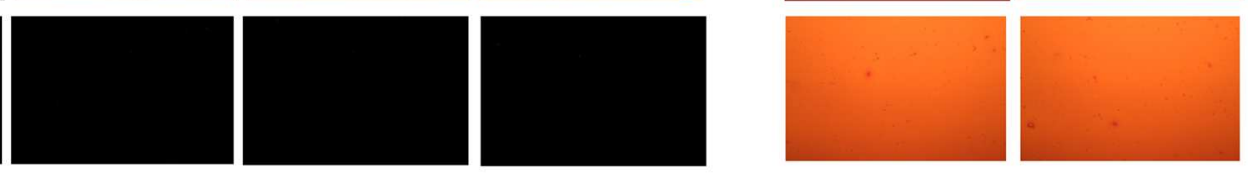

Figure S2: (A) Polarized Optical Microscopy (POM) images of capillaries filled with $5 \mathrm{mg} / \mathrm{mL}$ P3HT/Chloroform solutions processed as indicated, before filling. Angles refer to angle of stage as it rotates away from analyzer. (B) Images taken with only one polarizer, showing linear dichroism as film is rotated. 
(a)

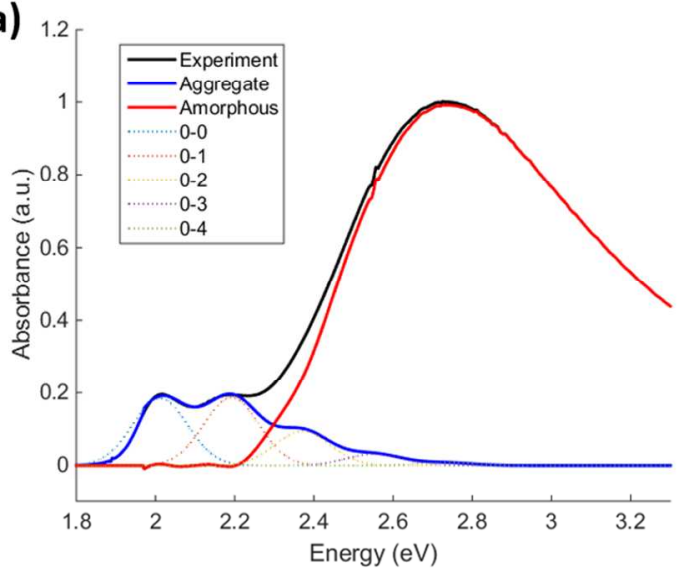

(c)
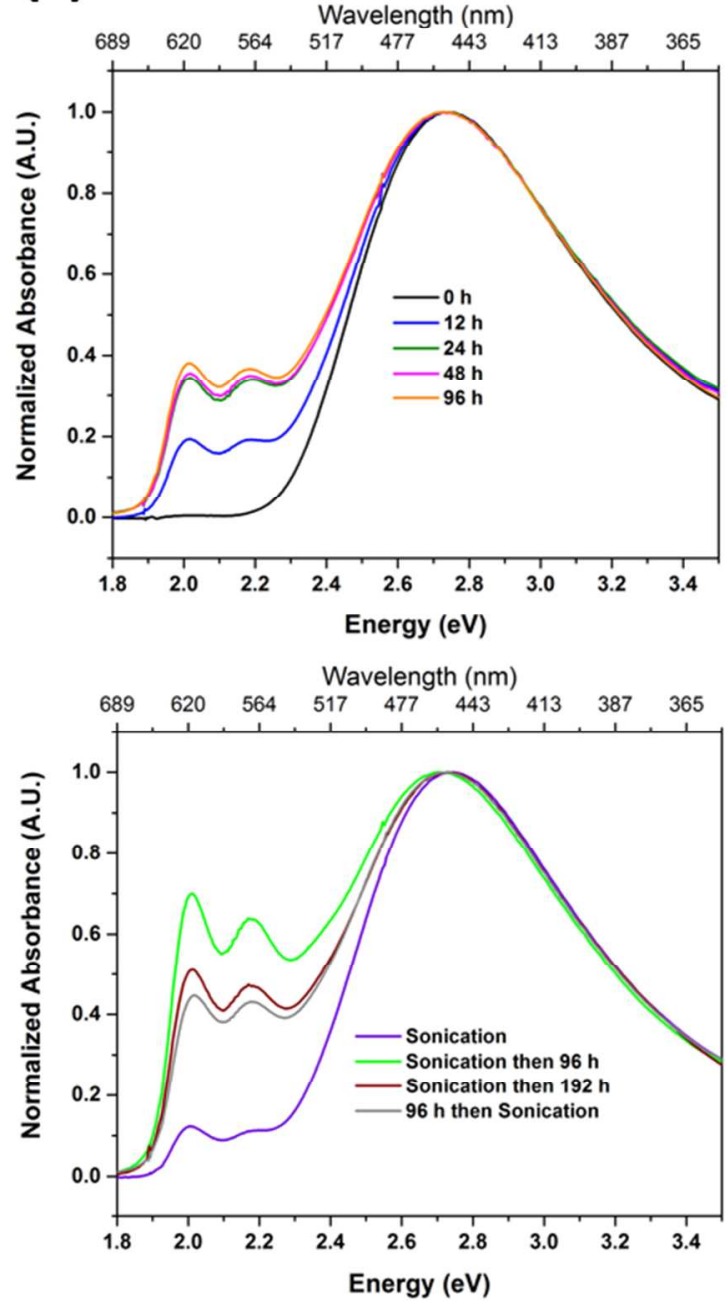

(b)

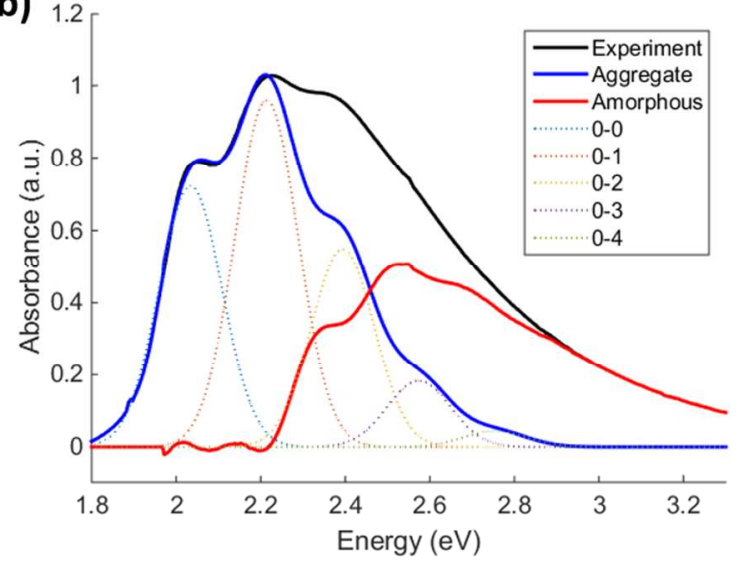

Films

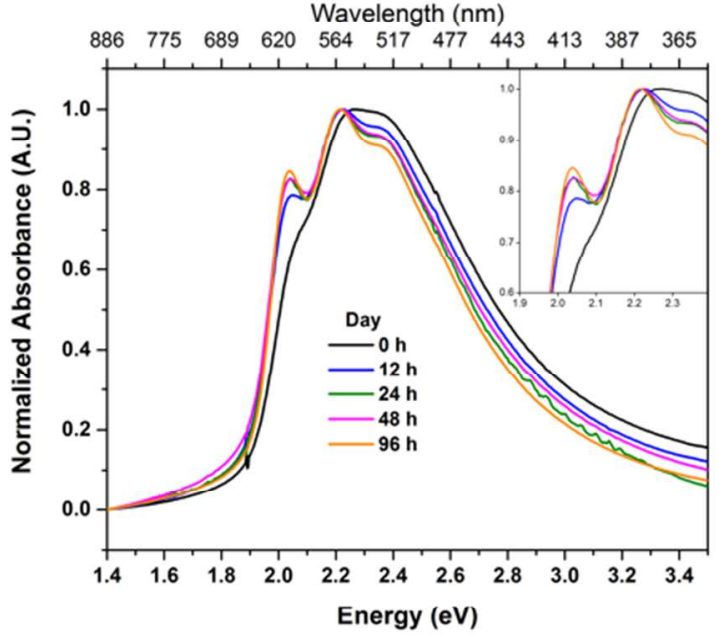

Wavelength $(\mathrm{nm})$

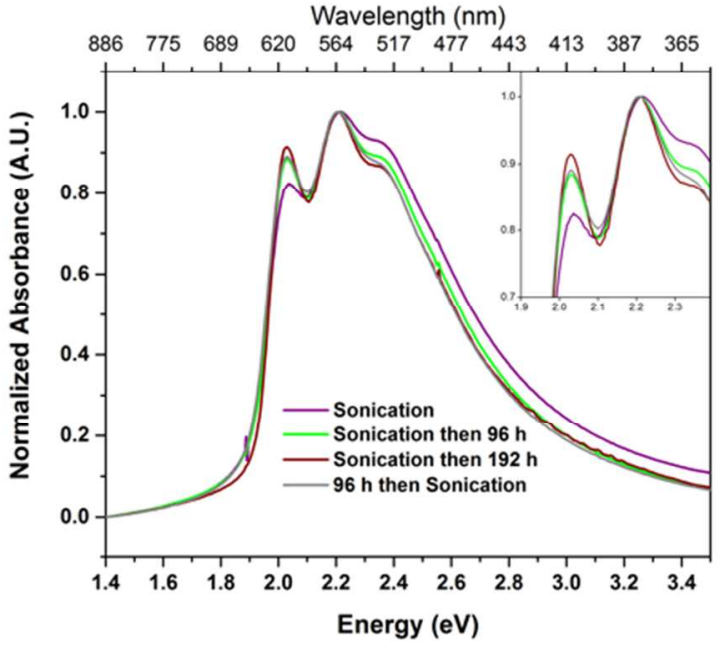

Figure S3: (A) Example of Franck-Condon fitting of normalized UV-Vis absorption spectra for obtaining percent aggregates in P3HT / Chloroform solution (a) and film (b) after 12 hours of aging, using methods described in literature: ${ }^{2}$ (c) UV-vis curves for all samples. 


$$
A(E) \propto \sum_{m=0}\left(\frac{S^{m}}{m !}\right)\left(1-\frac{W e^{-S}}{2 E_{p}} \sum_{n \neq m} \frac{S^{n}}{n ! n-m}\right)^{2} \exp \left(\frac{\left(E-E_{0-0}-m E_{p}-\frac{1}{2} W S^{m} e^{-S}\right)^{2}}{2 \sigma^{2}}\right)
$$

Parameters for the fit include:

$M=5$

$\mathrm{N}=10$

$\mathrm{S}=1$

$\mathrm{Ep}=0.18$ 

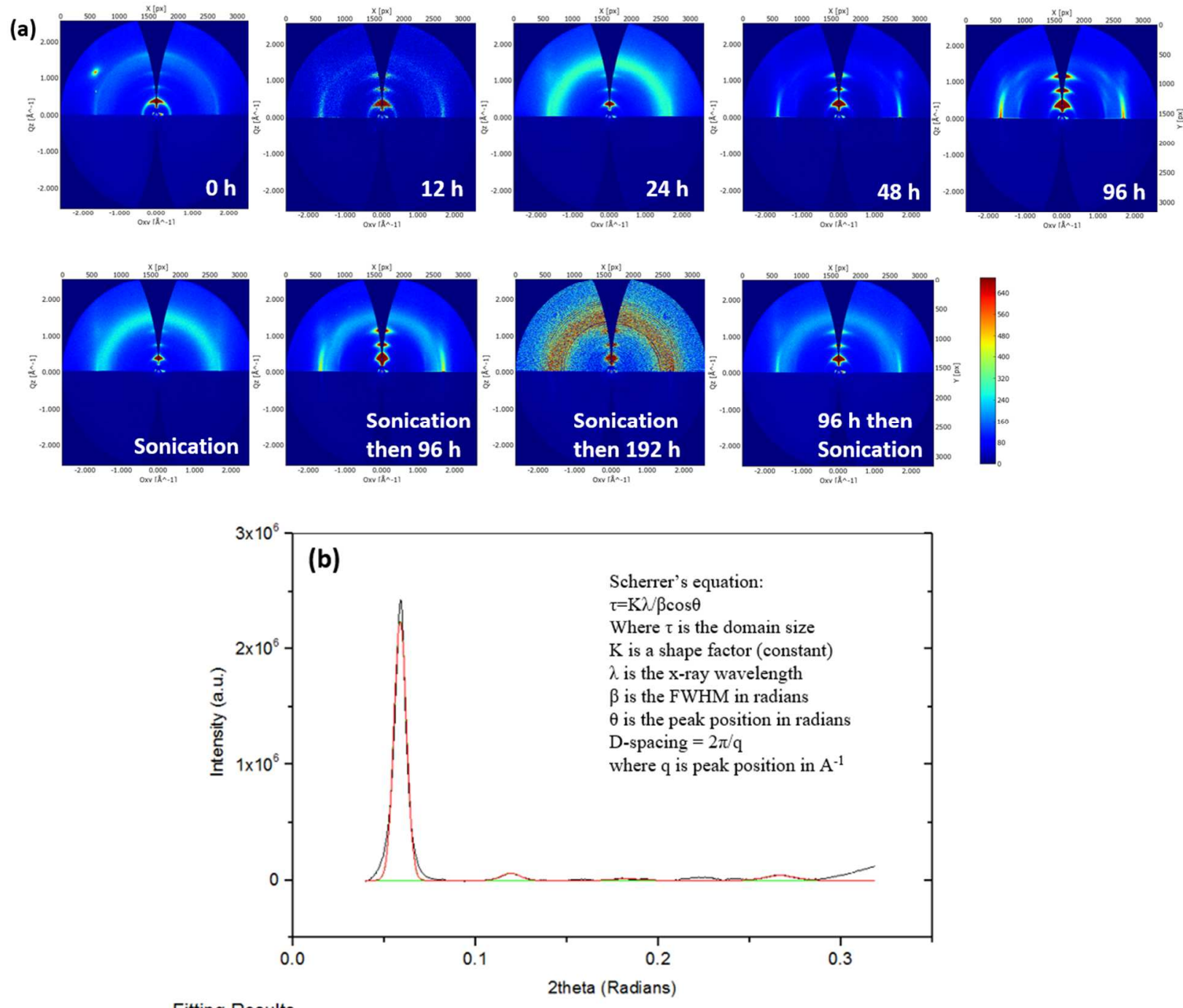

\begin{tabular}{|c|c|c|c|c|c|c|}
\hline Peak Index & Peak Type & Area Intg & FWHM & Max Height & Center Grvty & Area IntgP \\
\hline 1 & Gaussian & 19295.55304 & 0.00808 & $2.24232 \mathrm{E} 6$ & 0.05876 & 91.38982 \\
\hline 2 & Gaussian & 754.45696 & 0.01167 & 60722.69696 & 0.11935 & 3.57335 \\
\hline 3 & Gaussian & 228.65783 & 0.01755 & 12241.50051 & 0.18358 & 1.083 \\
\hline 4 & Gaussian & 834.79176 & 0.01881 & 41686.87363 & 0.26662 & 3.95384 \\
\hline
\end{tabular}

Figure S4: (A) All 2-D GIWAXS diffraction patterns. Note: Sonication then $192 \mathrm{~h}$ sample has lower signal to noise ratio, possibly due to an abnormally thin region of film that was exposed or an errant shorter beam time exposure. (B) Sample plot of 2-D images reduced to 1-D plots via integration of cake segments and analyzed using Origin Pro software for peak fitting. 

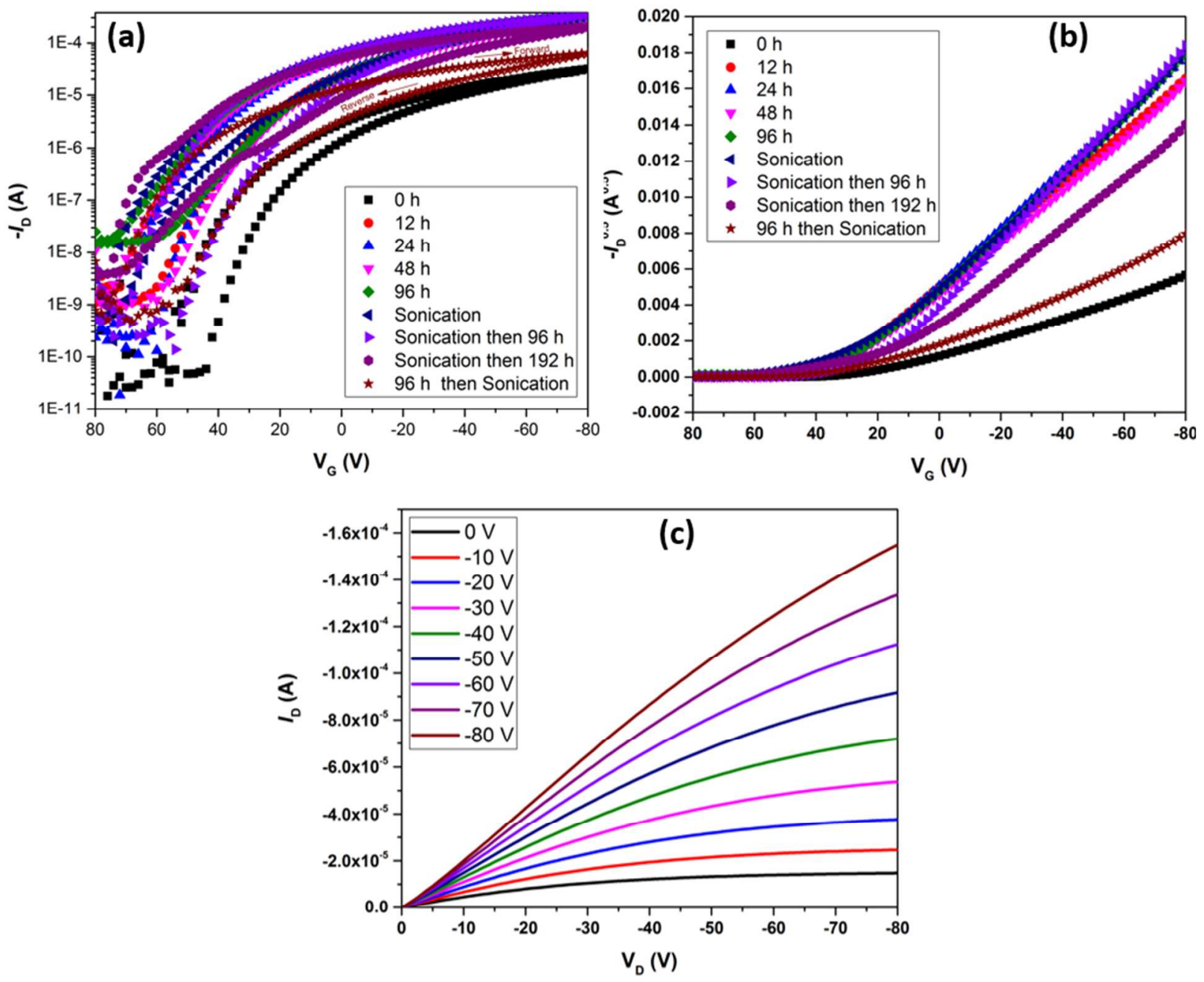

Figure S5: (a) Transfer characteristics of representative P3HT OFET devices $\left(\mathrm{V}_{\mathrm{D}}=-80 \mathrm{~V}\right)$ swept in both forward ( 80 to $-80 \mathrm{~V}$ ) and backward (-80 to $80 \mathrm{~V})$ directions. (b) Square root of drain current plotted vs $\mathrm{V}_{\mathrm{G}}$ in backward direction, used to calculate slope for mobility. (c) Output characteristics of a Sonicated then $96 \mathrm{~h}$ aged sample.

Table S1: Threshold Voltages and On/Off Ratios

\begin{tabular}{|l|c|c|c|c|}
\hline & $\mathbf{V}_{\mathbf{T}}$ & $\begin{array}{c}\mathbf{V}_{\mathbf{T}} \text { Standard } \\
\text { Deviation }\end{array}$ & On/Off Ratio & $\begin{array}{c}\text { On/Off Ratio } \\
\text { Standard Deviation }\end{array}$ \\
\hline $\mathrm{Oh}$ & $2.20 \mathrm{E}+01$ & $2.34 \mathrm{E}+00$ & $6.67 \mathrm{E}+06$ & $1.00 \mathrm{E}+07$ \\
\hline $12 \mathrm{~h}$ & $3.16 \mathrm{E}+01$ & $2.82 \mathrm{E}+00$ & $2.10 \mathrm{E}+05$ & $2.41 \mathrm{E}+05$ \\
\hline $24 \mathrm{~h}$ & $2.75 \mathrm{E}+01$ & $2.08 \mathrm{E}+00$ & $6.78 \mathrm{E}+06$ & $7.82 \mathrm{E}+06$ \\
\hline $48 \mathrm{~h}$ & $3.13 \mathrm{E}+01$ & $8.76 \mathrm{E}-01$ & $1.04 \mathrm{E}+05$ & $8.45 \mathrm{E}+04$ \\
\hline $96 \mathrm{~h}$ & $3.33 \mathrm{E}+01$ & $2.56 \mathrm{E}+00$ & $3.99 \mathrm{E}+04$ & $1.53 \mathrm{E}+04$ \\
\hline Sonication & $2.69 \mathrm{E}+01$ & $1.83 \mathrm{E}+00$ & $1.95 \mathrm{E}+05$ & $1.43 \mathrm{E}+05$ \\
\hline Sonication then $96 \mathrm{~h}$ & $2.48 \mathrm{E}+01$ & $2.97 \mathrm{E}+00$ & $3.84 \mathrm{E}+06$ & $3.74 \mathrm{E}+06$ \\
\hline Sonication then 192 $\mathrm{h}$ & $2.76 \mathrm{E}+01$ & $8.47 \mathrm{E}-01$ & $1.16 \mathrm{E}+05$ & $1.01 \mathrm{E}+05$ \\
\hline $96 \mathrm{~h}$ then Sonication & $2.29 \mathrm{E}+01$ & $4.36 \mathrm{E}-03$ & $2.86 \mathrm{E}+05$ & $2.26 \mathrm{E}+05$ \\
\hline
\end{tabular}



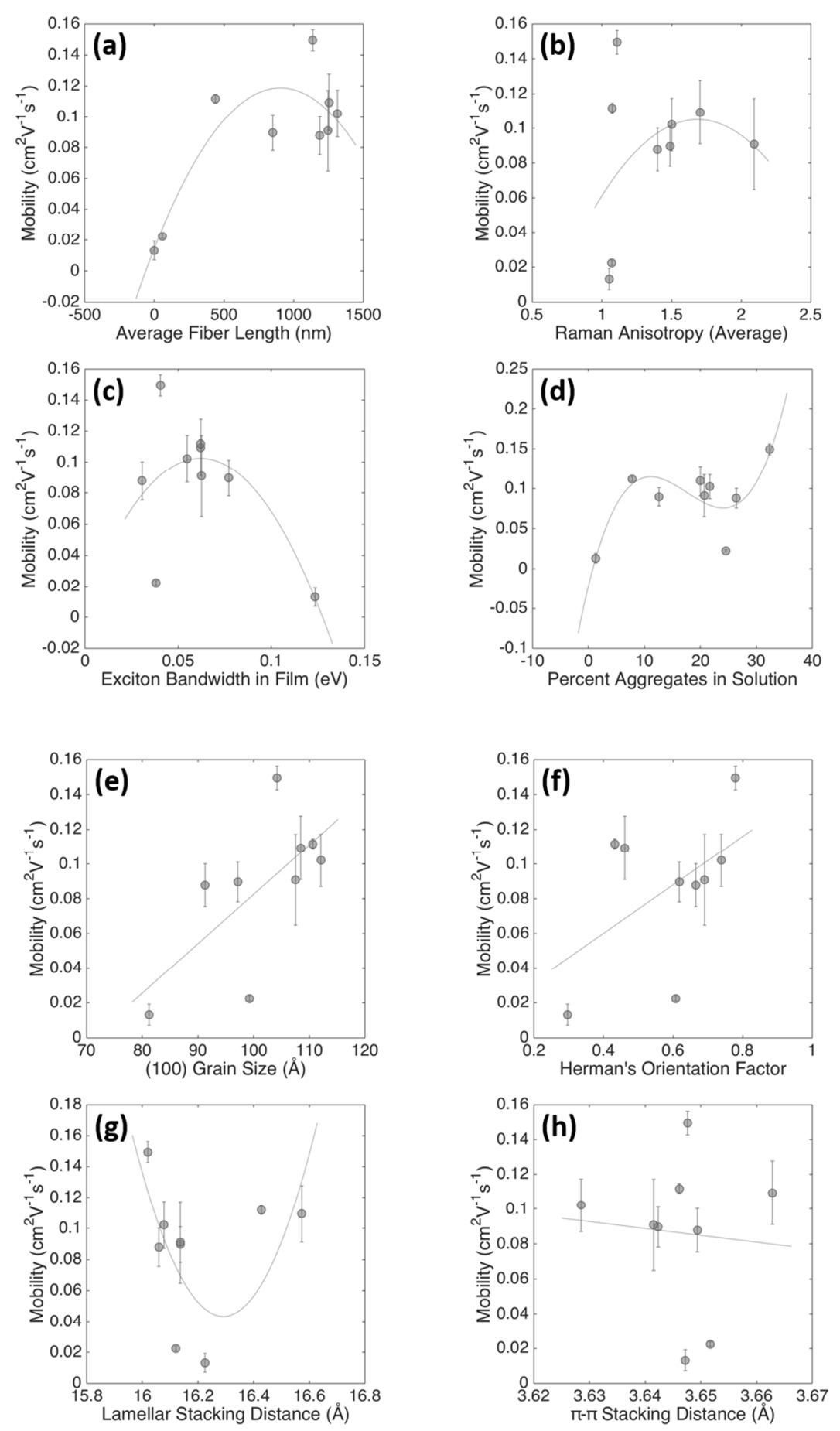

Figure S6. Mobility as a function of (a) average fiber length, (b) Raman anisotropy, (c) film exciton bandwidth, (d) percent aggregates in solution, (e) (100) grain size, (f) Herman's Orientation Factor, (g) lamellar stacking distance, and (h) $\pi-\pi$ stacking distance. 


\begin{tabular}{|lc|}
\hline Sample & $\begin{array}{c}\text { Persistence } \\
\text { Length (nm) }\end{array}$ \\
\hline $\mathbf{1 2} \mathbf{~ h}$ & 2469 \\
$\mathbf{2 4} \mathbf{~ h}$ & 2428 \\
\hline $\mathbf{9 6} \mathrm{h}$ & 3580 \\
\hline Sonication & 1231 \\
\hline Sonicated then $96 \mathrm{~h}$ & 4259 \\
\hline Sonication then 192h & 1313 \\
\hline 96 h then Sonication & 816 \\
\hline
\end{tabular}

Figure S7: Persistence lengths were calculated from AFM images using a fit of the mean square end-to-end distance function in FiberApp, and were taken at the processing length which yielded the fit with the lowest error. Sample aged for $0 \mathrm{~h}$ gave no visible fiber to measure.

Persistence lengths were mostly greater than $800 \mathrm{~nm}$, in alignment with the fibers' low degree of curvature. The $\pi$ - $\pi$-stacking interactions responsible for holding fibers together must be somewhat compliant to shear forces during deposition, however, since a finite persistence length (some curvature) is observed. It is unlikely, however, that these shear forces are capable of breaking $\pi$ - $\pi$-stacking interactions, given that fiber length increases with aging time in the postdeposition solid state. 


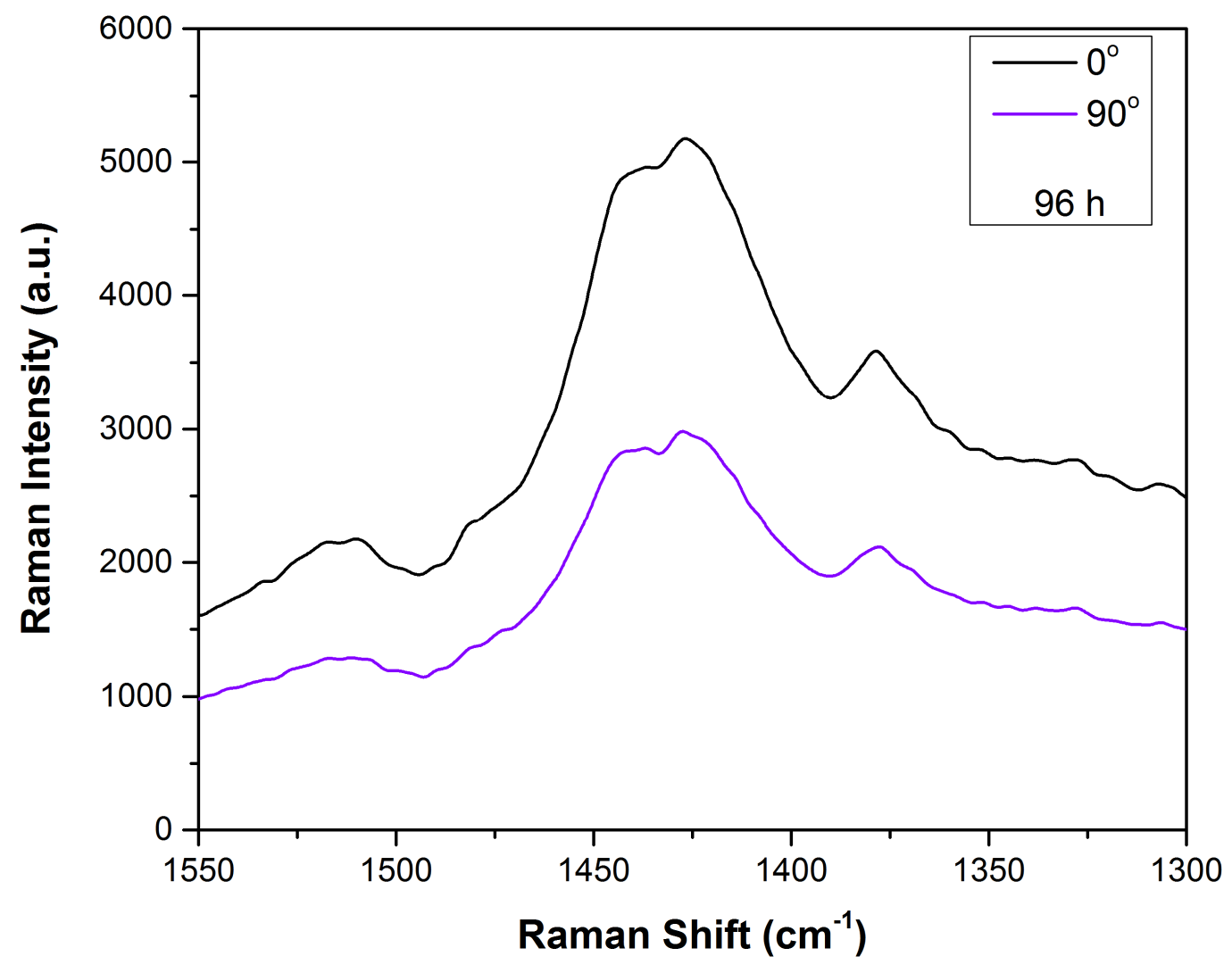

Figure S8: Example of Raman spectra obtained from P3HT film spin coated from solution aged $96 \mathrm{~h}$. Region of interest is $\mathrm{C}=\mathrm{C}$ double bond stretch: peaks fit from 1495 to $1390 \mathrm{~cm}^{-1}$ with Lorentzian curves to obtain peak height and compare for highest peak vs when sample was rotated by a further $90^{\circ}$.

\section{References:}

(1) Kleinhenz, N.; Rosu, C.; Chatterjee, S.; Chang, M.; Nayani, K.; Xue, Z.; Kim, E.; Middlebrooks, J.; Russo, P. S.; Park, J. O.; Srinivasarao, M.; Reichmanis, E. Liquid Crystalline Poly(3-Hexylthiophene) Solutions Revisited: Role of Time-Dependent SelfAssembly. Chem. Mater. 2015, 27, 2687-2694.

(2) Turner, S. T.; Pingel, P.; Steyrleuthner, R.; Crossland, E. J. W.; Ludwigs, S.; Neher, D. Quantitative Analysis of Bulk Heterojunction Films Using Linear Absorption Spectroscopy and Solar Cell Performance. Adv. Funct. Mater. 2011, 21, 4640-4652. 